\title{
Nitrogen-Doped Porous Carbon Derived From Bimetallic Zeolitic Imidazolate Frameworks For Electrochemical $\mathrm{Li}^{+} / \mathrm{Na}^{+}$Storage
}

\section{Shuai Dong}

Hefei University of Technology

Jiewu Cui ( $\nabla$ jwcui@hfut.edu.cn )

Hefei University of Technology https://orcid.org/0000-0003-4613-4795

Dongbo Yu

Hefei University of Technology

\section{Zhongnan Cao}

Hefei University of Technology

\section{Cuiping Yu}

Hefei University of Technology

\section{Yong Zhang}

Hefei University of Technology

\section{Yucheng Wu}

Hefei University of Technology

\section{Research Article}

Keywords: Bimetallic zeolitic imidazolate frameworks, Nitrogen-doped porous carbon, Li-ion battery, Naion battery

Posted Date: September 22nd, 2021

DOl: https://doi.org/10.21203/rs.3.rs-898776/v1

License: (a) (i) This work is licensed under a Creative Commons Attribution 4.0 International License. Read Full License

Version of Record: A version of this preprint was published at Journal of Solid State Electrochemistry on January 21st, 2022. See the published version at https://doi.org/10.1007/s10008-021-05100-y. 


\section{Abstract}

Porous carbon is regarded as one of the most promising anode candidates for Li-ion battery and Na-ion battery. We herein demonstrate a series of nitrogen-doped porous carbon (NPC) by simply carbonizing bimetallic ZnCo-containing zeolitic imidazolate frameworks (ZnCo-ZIFs). The nitrogen content, specific surface area, pore size distribution and microstructure of prepared NPC are balanced by adjusting $\mathrm{Zn}^{2+} / \mathrm{Co}^{2+}$ molar ratio of $\mathrm{ZnCo-ZIFs} \mathrm{and} \mathrm{carbonization} \mathrm{process} \mathrm{parameters.} \mathrm{It} \mathrm{is} \mathrm{found} \mathrm{that} \mathrm{the} \mathrm{optimized}$ ZnCo-ZIF-derived NPC shows promise for electrochemical $\mathrm{Li}^{+} / \mathrm{Na}^{+}$storage, which could be attributed to the hierarchical porous structure, large specific surface area and relatively high $\mathrm{N}$-doping content.

\section{Introduction}

Li-ion batteries (LIBS) and Na-ion batteries (SIBs) are considered as the most promising representatives of secondary battery system, which are widely applied in smart grids, portable electronics and electrical vehicles [1, 2]. Transition metal oxides, tin, silicon and red phosphorus with high theoretical specific capacity, are common anode materials for LIBs [3-8]. However, during the ion intercalation, these electrodes usually suffer from severe volume expansion and voltage lag, leading to massive irreversible capacity loss and poor stability, and thus hampering their practical application seriously [9]. Different from LIBs, SIBs have much more sluggish electrochemical kinetics than LIBs, and the larger $\mathrm{Na}^{+}$ion radius results in more rapid capacity fading and structural degradation, which sets higher demands on the electrochemical properties of electrode materials [10-12]. For example, commercial graphite is available for LIBs but no longer suitable for SIBs. Instead, porous carbon has been attracted more attention, which not only owns good electronic conductivity and stability, but also improves ion diffusion and volumetric strain [13-15]. In addition, rational pore distribution, high electrical conductivity and heteroatom doping play positive roles in electrochemical performances [16-19]. Therefore, nanoporous carbon with optimized porous structure and heteroatom doping is expected to show more promise for electrochemical energy storage.

As a new type of porous crystal material, metal-organic frameworks (MOFs), assembled by the coordination bonds between organic ligands and inorganic metal ions/clusters, have developed rapidly in recent years [20-22]. Due to the unique structural characteristics, high porosity and specific surface area, MOFs and their derived materials are emerged as outstanding candidates in energy storage, gas separation and nanoreactor, etc. [23-26]. Particularly, ZIFs such as ZIF-8 and ZIF-67 have been extensively studied for energy applications. Benefiting from the N-containing imidazole rings with ZIFs, the derived nanoporous carbon can be self-doped by $\mathrm{N}$ heteroatom after a simple carbonization process. At a properly controlled carbonization temperature, NPC derived from Zn-containing ZIF-8 can basically inherit the pore structure of initial precursor, demonstrating large surface area and high $\mathrm{N}$-doping content. Whereas, the amorphous nature of ZIF-8-derived NPC causes low electrical conductivity, greatly suppressing the rate performance [24, 27]. By contrast, the reduced metal Co particles within ZIF-67 have strong catalytic effect of graphitization and even facilitate the formation of CNTs [28]. While the enhancement of electrical conductivity is actually at the cost of surface area and N-doping content, which 
also hampers the electrochemical storage performances. In view of this, a core-shell hybrid structure is designed to combine advantages of both ZIF-8-derived and ZIF-67-derived NPC [24, 29], but the synthesis of such core-shell hybrids requires stepwise procedures. Apart from the construction of core-shell hybrids, bimetallic ZnCo-ZIFs are used as unprecedented templates [30, 31]. The agglomeration of Co nanoparticles can be effectively inhibited, as a result, the ZnCo-ZIF-derived NPC inherit both merits of carbon independently from ZIF-8 and ZIF-67, and the features such as surface area, graphitization and Ndoping content can be well balanced. More importantly, the synthesis procedure of ZnCo-ZIF is very simple, and the $\mathrm{Zn} / \mathrm{Co}$ molar ratio can be easily adjusted.

To this end, here in this work, we employ bimetallic ZnCo-ZIFs to prepare nanoporous carbon for the anodes of LIBs and SIBs. By optimizing the $\mathrm{Zn} /$ Co molar ratio and carbonization temperature, the resulting NPC achieves desirable properties including high surface area and favorable porous structure as well as high $\mathrm{N}$-doping content, which endows with ample active sites, accessible charge transfer and ion diffusion, and thus exhibits excellent $\mathrm{Li}^{+} / \mathrm{Na}^{+}$storage performances.

\section{Experimental Section}

\subsection{Material preparation}

Zinc acetate dehydrate $\left(\mathrm{Zn}\left(\mathrm{CH}_{3} \mathrm{COO}\right)_{2} \cdot 2 \mathrm{H}_{2} \mathrm{O}\right)$, 2-methylimidazole (2-MelM), Cobalt acetate tetrahydrate $\left(\mathrm{Co}\left(\mathrm{CH}_{3} \mathrm{COO}\right)_{2} \cdot 4 \mathrm{H}_{2} \mathrm{O}\right)$, ethanol and other chemicals and raw materials were purchased from Sinopharm Chemical Reagent Co. Ltd (Shanghai, China). All chemicals were of analytical reagent grade and used directly without further purification.

\subsubsection{Synthesis of ZIF-8 and ZIF-67 polyhedra}

ZIF-8 polyhedra were prepared by the previously reported procedure with some modifications. $0.53 \mathrm{~g}$ of $\mathrm{Zn}\left(\mathrm{CH}_{3} \mathrm{COO}\right)_{2} \cdot 2 \mathrm{H}_{2} \mathrm{O}$ was dissolved in $6 \mathrm{ml}$ of deionized water, and $1.97 \mathrm{~g}$ of 2-methylimidazole (2-MelM) was dissolved in $30 \mathrm{ml}$ of deionized water. The two solutions were mixed together and kept at $5^{\circ} \mathrm{C}$ in a refrigerator for $24 \mathrm{~h}$. The formed white powders were washed with deionized water and ethanol for several times, collected through centrifugation and dried at $80^{\circ} \mathrm{C}$ in an oven overnight. A similar procedure was applied for the preparation of purple powders of $\mathrm{ZIF}-67$ polyhedra, expect that $\mathrm{Zn}\left(\mathrm{CH}_{3} \mathrm{COO}\right)_{2} \cdot 2 \mathrm{H}_{2} \mathrm{O}$ was replaced by $\mathrm{Co}\left(\mathrm{CH}_{3} \mathrm{COO}\right)_{2} \cdot 4 \mathrm{H}_{2} \mathrm{O}$.

\subsubsection{Synthesis of ZnCo-ZIF polyhedra}

The synthesis of ZnCo-ZIF polyhedra with different Zn/Co molar ratio (denoted as xZnyCo-ZIF, where $x \%$ and $\mathrm{y} \%$ were the percentages of $\mathrm{Zn}$ and $\mathrm{Co}$, respectively) was similar to that of $\mathrm{ZIF-8}$. Taking the synthesis of $80 \mathrm{Zn} 20 \mathrm{Co}-\mathrm{ZIF}$ for example. The mixture of $0.42 \mathrm{~g}$ of $\mathrm{Zn}\left(\mathrm{CH}_{3} \mathrm{COO}\right)_{2} \cdot 2 \mathrm{H}_{2} \mathrm{O}$ and $0.12 \mathrm{~g}$ of $\mathrm{Co}\left(\mathrm{CH}_{3} \mathrm{COO}\right)_{2} \cdot 4 \mathrm{H}_{2} \mathrm{O}$ was dissolved in $6 \mathrm{ml}$ of deionized water, and $1.97 \mathrm{~g}$ of 2-MelM was dissolved in 30 $\mathrm{ml}$ of deionized water. The two solutions were mixed and kept at $5^{\circ} \mathrm{C}$ in a refrigerator for $24 \mathrm{~h}$. The formed 
light purple powders were washed with deionized water and ethanol for several times, collected through centrifugation and dried at $80^{\circ} \mathrm{C}$. It was worth noting that the total molar amount of $\mathrm{Zn}\left(\mathrm{CH}_{3} \mathrm{COO}\right)_{2} \cdot 2 \mathrm{H}_{2} \mathrm{O}$ and $\mathrm{Co}\left(\mathrm{CH}_{3} \mathrm{COO}\right)_{2} \cdot 2 \mathrm{H}_{2} \mathrm{O}$ was fixed to be $2.4 \mathrm{mmol}$.

\subsubsection{Preparation of NPCs polyhedra}

Typically, the prepared ZnCo-ZIF were calcinated at different temperatures $\left(600,700,800\right.$ or $\left.900^{\circ} \mathrm{C}\right)$ under Ar atmosphere for $2 \mathrm{~h}$ with a heating rate of $5^{\circ} \mathrm{C} \mathrm{min}^{-1}$. Subsequently, the obtained black powders were added into a diluted $\mathrm{HNO}_{3}$ solution for $24 \mathrm{~h}$ at $80^{\circ} \mathrm{C}$ to remove $\mathrm{Zn}$ and Co species. Finally, the samples were dried at $80^{\circ} \mathrm{C}$ overnight and denoted as $\mathrm{NPC}(x \mathrm{Zn}-y \mathrm{Co})-\mathrm{T}$, where T represents the carbonization temperature.

\subsection{Materials characterization}

The phase of the samples was tested by X-ray diffraction (XRD, D/MAX2500 V, Rigaku, Japan) equipped with Cu-Ka radiation $(0.15418 \mathrm{~nm})$ at $40 \mathrm{kV}, 40 \mathrm{~mA}$. The morphology and structure of the samples was observed by field emission scanning electron microscope (FESEM, SU8020, Hitachi, Japan), field emission transmission electron microscope (FETEM, JEM-2100F, JEOL, Japan), energy dispersive spectroscopy (EDS, Inca, Oxford, UK) and Raman spectra (LabRAM HR Evolution, HORIBA JOBIN YVON). The state of the elements was characterized by X-ray photoelectron spectroscopy (XPS, ESCALAB250, Thermo, US). The thermal gravimetric analysis (TGA) was operated by simultaneous thermal analyzer (STA449F3, Netzsch, Germany). The specific surface area and pore size distribution of the samples were calculated by Brunauer-Emmett-Teller (BET) method with a gas sorption surface area and pore size analyzer (Quadrasorb-EVO).

\subsection{Electrochemical measurements}

The electrochemical behavior of NPCs was studied using CR2032 half coin cells with lithium foil or sodium foil as the counter and reference electrode. The electrode paste was prepared by mixing active materials (NPCs, $80 \mathrm{wt} . \%)$, conductive carbon black (10 wt.\%) and polyvinylidene fluoride (PVDF, $10 \mathrm{wt} . \%$ ) in $\mathrm{N}$-methylpyrrolidone. Then the slurry was blade casted onto copper foil uniformly and dried at $60^{\circ} \mathrm{C}$ for $12 \mathrm{~h}$ in a vacuum oven. The mass loading of NPC was about $1 \mathrm{mg} \mathrm{cm}^{-2}$. The electrolyte used in the cells was $\operatorname{LiPF}_{6}(1.0 \mathrm{M})$ in a mixture of ethylene carbonate and diethyl carbonate $(1: 1 \mathrm{vol} \%)$ for LIB, which was replaced by $\mathrm{NaClO}_{4}(1.0 \mathrm{M})$ in a mixture of ethylene carbonate and propylene carbonate $(1: 1 \mathrm{vol} \%)$ for SIB. The used separator was Whatman GF/D membrane. The cells assembly was operated in an argonfilled glove box with moisture and the oxygen content below $1 \mathrm{ppm}$. The galvanostatic charge and discharge (GCD) tests and rate capability were measured by a multichannel battery testing system (LANHE, CT-2001A) with a potential range between 0.01 to $3 \mathrm{~V}$, cyclic voltammograms (CV) curves and electrochemical impedance spectra (EIS, frequency ranging from $100 \mathrm{kHz}$ to $0.01 \mathrm{~Hz}$ ) were tested on a CHI760E electrochemical workstation.

\section{Results And Discussion}


The preparation process of NPCs was illustrated in Fig. 1. With the increase of Co percentage, the color of prepared ZIFs changed gradually from white (ZIF-8) to deep purple (ZIF-67) (Fig. S1), and the average diameters also increased (Fig. S2 and Fig. 2a). All the ZIFs were solid particles (Fig. 2b), and the EDS analysis in Fig. $2 \mathrm{c}$ indicated the uniform distribution of $\mathrm{C}, \mathrm{N}, \mathrm{Zn}$ and Co elements in precursor. In addition, all the XRD patterns of the as-prepared ZIF-8, ZIF-67 and ZnCo-ZIFs were matched well with that of the simulated ZIF-8 (Fig. S3).

Calcination temperatures and Zn/Co molar ratio of ZnCo-ZIF play the crucial role in the morphology, structure and properties of the derived NPC. Herein, 40Zn60Co-ZIF is selected as the typical example to investigate the influence of calcination temperatures. According to the TGA and derivative thermogravimetric analysis (Fig. S4), it was obvious to see two major steps of rapid weight loss during the heating treatment. The first step with weight loss approximate $9.6 \%$ could be assigned to the loss of crystal water and the absorbed water, and the second one with $35.6 \%$ weight loss corresponded to the decomposition of the organic species, resulting in the formation of NPCs. Therefore, the calcination temperatures of $40 Z n 60 \mathrm{Co}-Z \mathrm{IF}$ should be higher than $600^{\circ} \mathrm{C}$. Fig. S5 were SEM images of the resulting NPCs after annealing $40 Z n 60 \mathrm{Co}-\mathrm{ZIF}$ at $600,700,800$ and $900^{\circ} \mathrm{C}$. Slight shrinkage was observed in NPCs compared to their precursor, and carbon nanotubes (CNTs) appeared accordingly with calcination temperature, resulting from the catalytic function of $\mathrm{Co}$ [28-31].

The influence of Zn/Co molar ratio on the derived NPC was also investigated. As displayed in Fig. S5a, Fig. $\mathrm{S} 6$ and Fig. 3a, all the polyhedra had rough surface, while there was less or even no CNTs grown on the surface of NPCs such as NPC $(100 Z n)-600^{\circ} \mathrm{C}$ and NPC (80Zn-20Co)- $600^{\circ} \mathrm{C}$. The amount of CNTs increased with the increasing Co content, because the more Co content caused the agglomeration of Co clusters which boosted the catalytic effect on graphitization of carbon [32]. The TEM and HRTEM images in Fig. 3b-d further confirmed the existence of CNTs, and small amount of Co nanoparticles enwrapped by CNTs were retained after $\mathrm{HNO}_{3}$ etching process. Moreover, $\mathrm{C}$ and $\mathrm{N}$ elements were uniformly distributed in $\mathrm{NPC}(20 \mathrm{Zn}-80 \mathrm{Co})-600^{\circ} \mathrm{C}$ (Fig. 3e), indicating the self-doping of heteroatom $\mathrm{N}$.

Figure 4a shows the XRD patterns of NPC $(x Z n-y C o)-600^{\circ} \mathrm{C}$, all the XRD patterns of NPC exhibit two peaks around $26^{\circ}$ and $44^{\circ}$, corresponding to (002) and (101) planes of carbon, respectively. Particularly, another peak located at $\sim 22^{\circ}$ emerged for NPC $(100 \mathrm{Zn})-600^{\circ} \mathrm{C}$, suggesting the formation of amorphous carbon [33]. It was worth to note that the peak around $26^{\circ}$ became stronger with the increasing cobalt content, resulting from the graphitization of amorphous carbon by catalysis of Co nanoparticles [34]. In the Raman spectra (Fig. 4b), all the samples displayed two distinct peaks at 1353 and $1590 \mathrm{~cm}^{-1}$, which were the disordered carbon ( $D$ band) and the ordered graphitized carbon ( $G$ band), respectively. The intensity ratio of $D$ band and $G$ band $\left(I_{D} / I_{G}\right)$ reflects the crystal defects and graphitization degree of carbon materials. The decrease of $I_{D} / I_{G}$ values from 1.08 to 0.98 demonstrated the reduction of lattice defects and the improvement of the graphitization degree [35].

XPS was conducted to further analyze the chemical composition of all the NPC materials. Fig. S7a shows the survey spectrum of $\mathrm{NPC}(40 \mathrm{Zn}-60 \mathrm{Co})-\mathrm{T}\left(\mathrm{T}=600^{\circ} \mathrm{C}, 700^{\circ} \mathrm{C}, 800^{\circ} \mathrm{C}\right.$ and $900^{\circ} \mathrm{C}$,) the three main peaks 
correspond to the $\mathrm{C} 1 \mathrm{~s}, \mathrm{~N} 1 \mathrm{~s}$ and $\mathrm{O} 1 \mathrm{~s}$, revealing the effective removal of $\mathrm{Zn}$ and Co during the carbonization and acid washing processes. Fig S7b-e are the high-resolution C 1s XPS spectra, the peak centered at 284.8, 285.8 and $288.5 \mathrm{eV}$ correspond to $\mathrm{C}-\mathrm{C}$ bonds of $\mathrm{sp}^{2}$ carbon, $\mathrm{C}=\mathrm{O}$ and $\mathrm{C}-\mathrm{N}$ functional groups, respectively [19]. The small peak at $291.7 \mathrm{eV}$ can be ascribed to $\pi-\pi$ electronic transitions [35]. Fig. S8a-d show the N 1s XPS spectrum of NPC(40Zn-60Co)-T, the N 1 s spectrum can be fitted into three peaks, including pyridinic $\mathrm{N}(398.6 \pm 0.1 \mathrm{eV})$, pyrrolic $\mathrm{N}(399.9 \pm 0.1 \mathrm{eV})$ and graphitic $\mathrm{N}(400.7 \pm 0.4 \mathrm{eV})$ $[36,37]$. The detailed N content values of ZIF(40Zn-60Co)-T-derived NPCs are summarized in Fig. S8e and Table S1. Obviously, the increase of annealing temperature leads to the decrease of nitrogen content in carbon materials because of the breakage of C-N bond at high temperature, thus NPC $(40 \mathrm{Zn}-60 \mathrm{Co})-600^{\circ} \mathrm{C}$ has $10.74 \%$ of $\mathrm{N}$-doping content, which is higher than $9.77 \%$ for NPC $(40 \mathrm{Zn}-60 \mathrm{Co})-700^{\circ} \mathrm{C}, 5.90 \%$ for NPC $(40 Z n-60 \mathrm{Co})-800^{\circ} \mathrm{C}$ and $4.90 \%$ for NPC $(40 Z n-60 \mathrm{Co})-900^{\circ} \mathrm{C}$. In addition, the proportion of graphitic $\mathrm{N}$ in the total nitrogen content also increases from $14.3-47.5 \%$ with the increase of calcination temperature, stemming from the transformation of pyrrolic $\mathrm{N}$ and pyridinic $\mathrm{N}$ into graphitic $\mathrm{N}$ [38]. The overview XPS spectra of $\mathrm{NPC}(x Z \mathrm{Zn}-y \mathrm{Co})-600^{\circ} \mathrm{C}$ with different $\mathrm{Zn} / \mathrm{Co}$ molar ratio are shown in Fig. S9a. Similar to NPC(40Zn-60Co)-T, four peaks were fitted in the high-resolution C 1s XPS spectrum of NPC $(x Z n-$ $y \mathrm{Co})-600^{\circ} \mathrm{C}$ (Fig. S9b-f) and three peaks were also in high-resolution N 1s spectra (Fig. 4c, Fig. S10). The total $\mathrm{N}$-doping content gradually raised with the increasing $\mathrm{Zn} / \mathrm{Co}$ molar ratio (Fig. $4 \mathrm{~d}$ and Table S2), because the existence of cobalt also result in the fracture of $\mathrm{C}-\mathrm{N}$ bond, which shows similar effect as high temperature. Note that pyrrolic $\mathrm{N}$ and pyridinic $\mathrm{N}$ can not only absorb $\mathrm{Li}^{+} / \mathrm{Na}^{+}$ions to afford additional capacity, but also promote the ion diffusion for rate performance; in addition, graphitic $\mathrm{N}$ can enhance the electronic conductivity [17].

The specific surface area and porous structure also play the important role on the $\mathrm{Li}^{+} / \mathrm{Na}^{+}$storage performance, which are evaluated by $\mathrm{N}_{2}$ adsorption-desorption analysis. NPC (40Zn-60Co)- $600^{\circ} \mathrm{C}$, NPC (40Zn-60Co)-700 $\mathrm{C}, \mathrm{NPC}(40 \mathrm{Zn}-60 \mathrm{Co})-800^{\circ} \mathrm{C}$ and NPC(40Zn-60Co)-900 ${ }^{\circ} \mathrm{C}$ have $313.0,259.4,363.1$ and $411.0 \mathrm{~m}^{2} \mathrm{~g}^{-1}$ of specific surface area, respectively (Fig. S11). In addition, the specific surface areas of NPC $(100 Z n)-600^{\circ} \mathrm{C}, \mathrm{NPC}(80 \mathrm{Zn}-20 \mathrm{Co})-600^{\circ} \mathrm{C}, \mathrm{NPC}(60 \mathrm{Zn}-40 \mathrm{Co})-600^{\circ} \mathrm{C}, \mathrm{NPC}(20 \mathrm{Zn}-80 \mathrm{Co})-600^{\circ} \mathrm{C}$ and $\mathrm{NPC}(100 \mathrm{Co})-600^{\circ} \mathrm{C}$ are determined as $16.9,21.1,193.5,313.0$ and $352.8 \mathrm{~m}^{2} \mathrm{~g}^{-1}$, respectively (Fig. S12). We can see Zn-rich NPC(100Zn)-600 ${ }^{\circ} \mathrm{C}$ and NPC(80Zn-20Co)-600 ${ }^{\circ} \mathrm{C}$ show very low specific surface area, which is caused by their poor catalytic by Co to the formation of graphite carbon[39]. Very interesting, all samples demonstrate a kind of hierarchically porous structure, as micropores can supply numerous electroactive sites for high capacity, and mesopores can boost the ion transfer for superior rate performance [40].

The electrochemical performance of $\mathrm{NPC}(x \mathrm{Zn}-y \mathrm{Co})-\mathrm{T}$ for $\mathrm{Li}^{+}$storage are investigated by $\mathrm{CV}$ and GCD techniques in the potential range of 0.01-3.0 V vs. $\mathrm{Li}^{+} / \mathrm{Li}$. Fig. S13a shows the initial three $\mathrm{CV}$ curves of $\mathrm{NPC}(20 \mathrm{Zn}-80 \mathrm{Co})-600^{\circ} \mathrm{C}$ at a scan rate of $0.1 \mathrm{mV} \mathrm{s}^{-1}$, an obvious peak appears around $0.6 \mathrm{~V}$ at the first cycle, which is due to the formation of solid-electrolyte-interphase (SEI) film on the surface of the electrode, and the peak near $0 \mathrm{~V}$ results from insertion of $\mathrm{Li}^{+}$in the porous carbon [41]. The second cycle and the third cycle almost overlap each other, indicating the excellent electrochemical reversibility of 
$\mathrm{NPC}(20 \mathrm{Zn}-80 \mathrm{Co})-600^{\circ} \mathrm{C}$. Figure $5 \mathrm{a}$ shows the CV curves of NPC $(20 \mathrm{Zn}-80 \mathrm{Co})-600^{\circ} \mathrm{C}$ at different scan rates. The electrochemical reaction kinetics can be evaluated according to the following equations [42]:

$\mathrm{i}=a v^{\mathrm{b}}$

$\log i=b \log v+\log a(2)$

where $i$ and $v$ are the response current and scan rate, respectively, $a$ and $b$ are adjustable constants in which $b$ value could be determined from the slope of log i versus $\log v$ curve from Eq. (2). If $b=0.5$, the reaction is subjected to diffusion-control behavior, while $b=1$, the kinetics is controlled by capacitive behavior [43]. Herein, the $b$ values at different potentials range from 0.5 to 1 (Fig. $5 \mathrm{~b}$ ), suggesting the coexistence of diffusion and capacitive controlled processes. In addition, the total capacity could be divided into a diffusion controlled part $\left(k_{1} v^{1 / 2}\right)$ and a capacitive controlled one $\left(k_{2} v\right)$ at a fixed potential $(\mathrm{V})$ according to the following equations [44]:

$\mathrm{i}(\mathrm{V})=\mathrm{k}_{1} \mathrm{v}^{1 / 2}+\mathrm{k}_{2} \mathrm{v}(3)$

$\mathrm{i}(\mathrm{V}) / \mathrm{v}^{1 / 2}=\mathrm{k}_{1}+\mathrm{k}_{2} \mathrm{v}^{1 / 2}$

It can be seen that the capacitive control behavior gradually dominates the total capacity, and the capacitive control contribution increases from $52.3 \%$ at $0.1 \mathrm{mV} \mathrm{s}^{-1}$ to $83.2 \%$ at $2 \mathrm{mV} \mathrm{s}^{-1}$ (Fig. $5 \mathrm{c}$ ), revealing the superior rate performance of NPC(20Zn-80Co)- $600^{\circ} \mathrm{C}$.

Figure $5 \mathrm{~d}$ shows the typical GCD curves of NPC(20Zn-80Co)- $600^{\circ} \mathrm{C}$ at the current density of $0.1 \mathrm{~A} \mathrm{~g}^{-1}$ for the first three cycles. The initial charging and discharging specific capacity of NPC(20Zn-80Co)- $600^{\circ} \mathrm{C}$ are 804.2 and $1251.9 \mathrm{~mA} \mathrm{~h} \mathrm{~g}^{-1}$ with the coulombic efficiency (CE) of $64 \%$, which is originated from the irreversible processes such as decomposition of electrolyte and the formation of SEI film [45]. The influence of calcination temperatures and the initial $\mathrm{Zn}^{2+} / \mathrm{Co}^{2+}$ molar ratios on the rate capability are investigated. Fig. S13b shows the rate capability of NPC(40Zn-60Co)-T from $0.1 \mathrm{~A} \mathrm{~g}^{-1}$ to $5 \mathrm{~A} \mathrm{~g}^{-1}$, it can be observed that NPC(40Zn-60Co)-600 ${ }^{\circ} \mathrm{C}$ delivers 786.0, 736.9, 634.9, 521.8, 401.1 and $254.1 \mathrm{~mA} \mathrm{~h} \mathrm{~g}^{-1}$ at current density of $0.1,0.2,0.5,1.0,2.0$ and $5.0 \mathrm{~A} \mathrm{~g}^{-1}$, respectively. When the current density returns to 0.1 $\mathrm{A} \mathrm{g}^{-1}$, a capacity as high as $783.6 \mathrm{~mA} \mathrm{~h} \mathrm{~g}^{-1}$ still can be achieved. NPC(40Zn-60Co)-600 ${ }^{\circ} \mathrm{C}$ has superior rate capability compared with other counterparts, thus proving the optimized calcination temperature of $600^{\circ} \mathrm{C}$. Secondly, the rate capability of $\operatorname{NPC}(x Z \mathrm{Zn}-y \mathrm{Co})-600^{\circ} \mathrm{C}$ derived from precursor with different $\mathrm{Zn}^{2+} / \mathrm{Co}^{2+}$ molar ratio are displayed in Fig. 5e. NPC(20Zn-80Co)-600 ${ }^{\circ} \mathrm{C}$ exhibits reversible capacity of $876.5,768.9,664.7,570.7,480.9$ and $352.6 \mathrm{~mA} \mathrm{~h} \mathrm{~g}^{-1}$ at current density of $0.1,0.2,0.5,1,2$ and $5 \mathrm{~A} \mathrm{~g}^{-1}$, respectively, which are higher than other $\mathrm{NPC}(x Z \mathrm{n}-y \mathrm{Co})-600^{\circ} \mathrm{C}$. More importantly, when the current density is back to $0.1 \mathrm{~A} \mathrm{~g}^{-1}, \mathrm{NPC}(20 \mathrm{Zn}-80 \mathrm{Co})-600^{\circ} \mathrm{C}$ shows a capacity of $857.9 \mathrm{~mA} \mathrm{~h} \mathrm{~g}{ }^{-1}$, which is closed to the initial specific capacity. The excellent $\mathrm{Li}^{+}$storage performance of $\mathrm{NPC}(20 \mathrm{Zn}-80 \mathrm{Co})-600^{\circ} \mathrm{C}$ results from the aforementioned high nitrogen content, big specific surface area, suitable porous structure and pore size.

Figure $\mathrm{S} 13 \mathrm{c}$ and Fig. $5 \mathrm{f}$ show the cycling performance of NPC(20Zn-80Co)-600 ${ }^{\circ} \mathrm{C}$ at low and high current densities, respectively. NPC(20Zn-80Co)- $600^{\circ} \mathrm{C}$ could retain $98.3 \%$ after 100 cycles at $0.1 \mathrm{~A} \mathrm{~g}^{-1}$ and 99.8 
$\%$ after 500 cycles at $1 \mathrm{~A} \mathrm{~g}^{-1}$. The coulombic efficiencies reach almost $100 \%$ after the first cycle, indicating the excellent long-term stability. The charge transfer kinetics of the NPC $(x Z n-y C o)-600^{\circ} \mathrm{C}$ are further investigated by EIS, it can be noticed from Fig. S13d that the Nyquist plots for all the samples are similar and each curve consists of a semicircle in the high frequency region and an approximate oblique line in the low frequency region. The semicircle of the high frequency region corresponds to the charge transfer resistance $\left(R_{c t}\right)$ generated by the contact between the active material and electrolyte solution, and the contact between the interfacial active material and the copper foil collector fluid. The slant area in the low frequency region represents the Warburg impedance $\left(Z_{w}\right)$, which is related to the diffusion of $\mathrm{Li}^{+}$into the electrode [46]. NPC(20Zn-80Co)-600 ${ }^{\circ} \mathrm{C}$ exhibits the minimum semicircle compared with that of other NPC, suggesting the minimum charge transfer resistance and Warburg resistance. It could be concluded that the unique hierarchical porous structure with a high specific surface area not only provides a rapid transport channel, but also reduces the transport path of $\mathrm{Li}^{+}$. In addition, the as-prepared $\mathrm{NPC}(20 \mathrm{Zn}-80 \mathrm{Co})-600^{\circ} \mathrm{C}$ has better $\mathrm{Li}^{+}$storage properties compared with other reported porous carbonbased materials (Table S3).

Meantime, NPC-(20Zn-80Co)-600 $\mathrm{C}$ are also suitable for electrochemical $\mathrm{Na}^{+}$storage. Fig. S14a shows the initial three $\mathrm{CV}$ curves at scan rate of $0.1 \mathrm{mV} \mathrm{s}^{-1}$, the first irreversible reduction peak around $0.6 \mathrm{~V}$ in the CV curve is mainly caused by the formation of SEI film [47] and the peak located around $0 \mathrm{~V}$ suggests the sodium ion insertion into NPC(20Zn-80Co) $-600^{\circ} \mathrm{C}$ [48]. In addition, the CV curves almost overlapped with each other in the second and third cycles, indicating that NPC $(20 \mathrm{Zn}-80 \mathrm{Co})-600^{\circ} \mathrm{C}$ electrode materials have good cycling performance in the process of $\mathrm{Na}^{+}$intercalation/de-intercalation. In addition, a rectangular area can be observed in potential range of 1.5-3 V, suggesting a capacitive behavior [49]. Figure 6 a illustrates the CV curves of NPC(20Zn-80Co) $-600^{\circ} \mathrm{C}$ at different scan rates ranging from 0.1 to $2.0 \mathrm{mV} \mathrm{s}^{-1}$ with the similar shape, revealing its high reversibility and good repeatability in the electrochemical reactions. Similar to $\mathrm{Li}^{+}$storage, the energy storage mechanism in $\mathrm{Na}^{+}$storage is also controlled by both diffusion behavior and capacitance behavior (Fig. 6b). As demonstrated in Fig. 6c, through quantitative analysis of capacitance control behavior and diffusion control behavior, the behavior of capacitive control accounts for a large part of the total capacity at each scan rate, ranging from $53.9 \%$ (at $0.1 \mathrm{mV} \mathrm{s}^{-1}$ ) to $83.2 \%$ (at $2.0 \mathrm{mV} \mathrm{s}^{-1}$ ), which indicates high proportion of pseudocapacitance of the total capacitance contribution.

Figure $6 \mathrm{~d}$ illustrates the first three GCD curves of NPC(20Zn-80Co)-600 ${ }^{\circ} \mathrm{C}$ at a current density of $0.02 \mathrm{~A} \mathrm{~g}^{-}$ 1 , the initial discharging and charging specific capacity are 872.0 and $377.2 \mathrm{~mA} \mathrm{~h} \mathrm{~g}-1$, respectively, and the initial coulombic efficiency is $43.3 \%$ (Fig. S14a). NPC(20Zn-80Co)-600 $\mathrm{C}$ also presents excellent rate capability and cycling stability. NPC(20Zn-80Co)-600 ${ }^{\circ} \mathrm{C}$ delivers reversible capacity of $416.1,291.6,245.0$, 206.6, 172.7, 144.0, 125.2 and $113.0 \mathrm{~mA} \mathrm{~h} \mathrm{~g}^{-1}$ at current densities of $0.02,0.05,0.1,0.2,0.5,1,1.5$ and 2 $\mathrm{A} \mathrm{g}^{-1}$, respectively, which could still retain to $276 \mathrm{~mA} \mathrm{~h} \mathrm{~g}^{-1}$ when the current density immediately returns to $0.02 \mathrm{~A} \mathrm{~g}^{-1}$. after 450 cycles at $0.05 \mathrm{~A} \mathrm{~g}^{-1}$, it exhibits a capacity of $218.0 \mathrm{~mA} \mathrm{~h} \mathrm{~g}^{-1}$ (Fig. S14b), and a reversible specific capacity of $117.8 \mathrm{~mA} \mathrm{~h} \mathrm{~g}^{-1}$ could be retained after 1000 cycles at high current density 
of $1 \mathrm{~A} \mathrm{~g}^{-1}$ (Fig. 6f). In addition, the coulombic efficiency is almost closed to $100 \%$ after the first cycle, demonstrating that NPC $(20 \mathrm{Zn}-80 \mathrm{Co})-600^{\circ} \mathrm{C}$ has remarkable long-term cycling stability. The $\mathrm{Na}^{+}$storage performance of $\mathrm{NPC}(20 \mathrm{Zn}-80 \mathrm{Co})-600^{\circ} \mathrm{C}$ is also comparable with other reported porous carbon-based materials (Table S4).

\section{Conclusions}

In summary, ZnCo-ZIF-derived NPC are prepared by a simple carbonization treatment. The Zn/Co molar ratio within the initial ZnCo-ZIF and the carbonization temeperature are optimized to balance the morphology, nitrogen content, specific surface area and porous structure of the derived NPC. It is found that NPC $(20 \mathrm{Zn}-80 \mathrm{Co})-600^{\circ} \mathrm{C}$ shows excellent electrochemical properties for $\mathrm{Li}^{+} / \mathrm{Na}^{+}$storage. The asprepared NPC are expected to be promising alternatives for the application in energy storage and other related fields.

\section{Declarations}

\section{Declaration of Competing Interest}

The authors declare that they have no known competing financial interests or personal relationships that could have appeared to influence the work reported in this paper.

\section{Acknowledgements}

We acknowledge the funding support from the National Natural Science Foundation of China (U1810204), the Natural Science Foundation of Anhui Province (2108085MB45) and the Fundamental Research Funds for the Central Universities (JZ2020HGTB0059, PA2021 KCPY0044 and PA2020GDSK0087). We also would like to thank the financial support from the 111 Project (B18018).

\section{References}

1. Yu ZL, Xin S, You Y, Yu L, Lin Y, Xu DW, Qiao C, Huang ZH, Yang N, Yu SH, Goodenough JB (2016) loncatalyzed synthesis of microporous hard carbon embedded with expanded nanographite for enhanced lithium/sodium storage. J Am Chem Soc 138:14915-14922

2. Goodenough JB, Park KS (2013) The Li-ion rechargeable battery: a perspective. J Am Chem Soc 135:1167-1176

3. Idota Y, Kubota T, Matsufuji A, Maekawa Y, Miyasaka T (1997) Tin-based amorphous oxide: a highcapacity lithium-ion storage material. Science 276:1395-1397

4. Chan CK, Peng H, Liu G, Mcllwrath K, Zhang XF, Huggins RA, Cui Y (2008) High-performance lithium battery anodes using silicon nanowires. Nat Nanotechnol 3:31-35

5. Li W, Hu S, Luo X, Li Z, Sun X, Li M, Liu F, Yu Y (2017) Confined amorphous red phosphorus in MOFderived $\mathrm{N}$-doped microporous carbon as a superior anode for sodium-ion battery. Adv Mater 
29:1605820

6. Poizot P, Laruelle S, Grugeon S, Dupont L, Tarascon JM (2000) Nano-sized transition-metal oxides as negative-electrode materials for lithium-ion batteries. Nature 407:496-499

7. Zhang L, Wu HB, Madhavi S, Hng HH, Lou XW (2012) Formation of $\mathrm{Fe}_{2} \mathrm{O}_{3}$ microboxes with hierarchical shell structures from metal-organic frameworks and their lithium storage properties. J Am Chem Soc 134:17388-17391

8. Fan J, Wang T, Yu C, Tu B, Jiang Z, Zhao D (2004) Ordered, nanostructured Tin-based oxides/carbon composite as the negative-electrode material for lithium-ion batteries. Adv Mater 16:1432-1436

9. Zhao Y, Li X, Yan B, Xiong D, Li D, Lawes S, Sun X (2016) Recent developments and understanding of novel mixed transition-metal oxides as anodes in lithium ion batteries. Adv Energy Mater 6:1502175

10. Mahmood A, Li S, Ali Z, Tabassum H, Zhu B, Liang Z, Meng W, Aftab W, Guo W, Zhang H, Yousaf M, Gao S, Zou R, Zhao Y (2019) Ultrafast sodium/potassium-ion intercalation into hierarchically porous thin carbon shells. Adv Mater 31:e1805430

11. Palomares V, Serras P, Villaluenga I, Hueso KB, Carretero-González J, Rojo T (2012) Na-ion batteries, recent advances and present challenges to become low cost energy storage systems. Energy Environ Sci 5:5884-5901

12. Tang K, Fu L, White RJ, Yu L, Titirici MM, Antonietti M, Maier J (2012) Hollow carbon nanospheres with superior rate capability for sodium-based batteries. Adv Energy Mater 2:873-877

13. Hu X, Sun X, Yoo SJ, Evanko B, Fan F, Cai S, Zheng C, Hu W, Stucky GD (2019) Nitrogen-rich hierarchically porous carbon as a high-rate anode material with ultra-stable cyclability and high capacity for capacitive sodium-ion batteries. Nano Energy 56:828-839

14. Li D, Chen H, Liu G, Wei M, Ding L, Wang S, Wang H (2015) Porous nitrogen doped carbon sphere as high performance anode of sodium-ion battery. Carbon 94:888-894

15. Zou G, Hou H, Cao X, Ge P, Zhao G, Yin D, Ji X (2017) 3D hollow porous carbon microspheres derived from Mn-MOFs and their electrochemical behavior for sodium storage. J Mater Chem A 5:2355023558

16. Guan BY, Yu XY, Wu HB, Lou XW (2017) Complex nanostructures from materials based on metalorganic frameworks for electrochemical energy storage and conversion. Adv Mater 29:1703614

17. Yu D, Shao Q, Song Q, Cui J, Zhang Y, Wu B, Ge L, Wang Y, Zhang Y, Qin Y, Vajtai R, Ajayan PM, Wang H, Xu T, Wu Y (2020) A solvent-assisted ligand exchange approach enables metal-organic frameworks with diverse and complex architectures. Nat Commun 11:927

18. Kim J, Choi MS, Shin KH, Kota M, Kang Y, Lee S, Lee JY, Park HS (2019) Rational design of carbon nanomaterials for electrochemical sodium storage and capture. Adv Mater 31:1803444

19. Mao Y, Duan H, Xu B, Zhang L, Hu Y, Zhao C, Wang Z, Chen L, Yang Y (2012) Lithium storage in nitrogen-rich mesoporous carbon materials. Energy Environ Sci 5:7950

20. Wang H, Zhu QL, Zou R, Xu Q (2017) Metal-organic frameworks for energy applications. Chem 2:5280

Page 10/18 
21. Furukawa H, Cordova KE, O'Keeffe M, Yaghi OM (2013) The chemistry and applications of metalorganic frameworks. Science 341:1230444

22. Zhao R, Liang Z, Zou R, Xu Q (2018) Metal-organic frameworks for batteries. Joule 2:2235-2259

23. Li JR, Kuppler RJ, Zhou HC (2009) Selective gas adsorption and separation in metal-organic frameworks. Chem Soc Rev 38:1477-1504

24. Yang J, Zhang F, Lu H, Hong X, Jiang H, Wu Y, Li Y (2015) Hollow Zn/Co ZIF particles derived from core-shell ZIF-67@ZIF-8 as selective catalyst for the semi-hydrogenation of acetylene. Angew Chem Int Ed 54:10889-10893

25. Lu G, Hupp JT (2010) Metal-organic frameworks as sensors: a ZIF-8 based fabry-perot device as a selective sensor for chemical vapors and gases. J Am Chem Soc 132:7832-7833

26. Zhang X, Chen A, Zhong M, Zhang Z, Zhang X, Zhou Z, Bu XH (2018) Metal-organic frameworks (MOFs) and MOF-derived materials for energy storage and conversion. Electrochem Energy Rev 2:29-104

27. Chen YZ, Wang C, Wu ZY, Xiong Y, Xu Q, Yu SH, Jiang HL (2015) From bimetallic metal-organic framework to porous carbon: high surface area and multicomponent active dopants for excellent electrocatalysis. Adv Mater 27:5010-5016

28. Chen YM, Yu L, Lou XW (2016) Hierarchical tubular structures composed of $\mathrm{Co}_{3} \mathrm{O}_{4}$ hollow nanoparticles and carbon nanotubes for lithium storage. Angew Chem Int Ed 55:5990-5993

29. Pan Y, Sun K, Liu S, Cao X, Wu K, Cheong WC, Chen Z, Wang Y, Li Y, Liu Y, Wang D, Peng Q, Chen C, Li Y (2018) Core-shell ZIF-8@ZIF-67-derived CoP nanoparticle-embedded N-doped carbon nanotube hollow polyhedron for efficient overall water splitting. J Am Chem Soc 140:2610-2618

30. Li Y, Jia B, Fan Y, Zhu K, Li G, Su CY (2018) Bimetallic zeolitic imidazolite framework derived carbon nanotubes embedded with Co nanoparticles for efficient bifunctional oxygen electrocatalyst. Adv Energy Mater 8:1702048

31. Ahn SH, Klein MJ, Manthiram A, 1D (2017) Co- and N-doped hierarchically porous carbon nanotubes derived from bimetallic metal organic framework for efficient oxygen and tri-iodide reduction reactions. Adv Energy Mater 7:1601979

32. Yang J, Gao H, Men S, Shi Z, Lin Z, Kang X, Chen S (2018) CoSe $e_{2}$ nanoparticles encapsulated by Ndoped carbon framework intertwined with carbon nanotubes: high-performance dual-role anode materials for both Li- and Na-ion batteries. Adv Sci 5:1800763

33. Jiang HL, Liu B, Lan YQ, Kuratani K, Akita T, Shioyama H, Zong F, Xu Q (2011) From metal-organic framework to nanoporous carbon: toward a very high surface area and hydrogen uptake. J Am Chem Soc 133:11854-11857

34. Xia BY, Yan Y, Li N, Wu HB, Lou XW, Wang X (2016) A metal-organic framework-derived bifunctional oxygen electrocatalyst. Nat Energy 1:15006

35. Liu YZ, Li GR, Chen ZW, Peng XS (2017) CNT-Threaded N-doped porous carbon film as binder-free electrode for high-capacity supercapacitor and Li-S battery. J Mater Chem A 5:9775-9784 
36. Scardamaglia M, Amati M, Llorente B, Mudimela P, Colomer JF, Ghijsen J, Ewels C, Snyders R, Gregoratti L, Bittencourt C (2014) Nitrogen ion casting on vertically aligned carbon nanotubes: tip and sidewall chemical modification. Carbon 77:319-328

37. Zhang XJ, Zhu G, Wang M, Li JB, Lu T, Pan LK (2017) Covalent-organic-frameworks derived N-doped porous carbon materials as anode for superior long-life cycling lithium and sodium ion batteries. Carbon 116:686-694

38. Parvez K, Yang S, Hernandez Y, Winter A, Turchanin A, Feng X, Müllen K (2012) Nitrogen-doped graphene and its iron-based composite as efficient electrocatalysts for oxygen reduction reaction. ACS Nano 6:9541-9550

39. Torad NL, Salunkhe RR, Li Y, Hamoudi H, Imura M, Sakka Y, Hu CC, Yamauchi Y (2014) Electric double-layer capacitors based on highly graphitized nanoporous carbons derived from ZIF-67. Chem Eur J 20:7895-7900

40. Wang C, Kaneti YV, Bando Y, Lin J, Liu C, Li J, Yamauchi Y (2018) Metal-organic framework-derived one-dimensional porous or hollow carbon-based nanofibers for energy storage and conversion. Mater Horiz 5:394-407

41. Yoo E, Kim J, Hosono E, Zhou H, Kudo T, Honma I (2008) Large reversible Li storage of graphene nanosheet families for use in rechargeable lithium ion batteries. Nano Lett 8:2277-2282

42. Yang M, Zhong Y, Ren J, Zhou X, Wei J, Zhou Z (2015) Fabrication of high-power Li-ion hybrid supercapacitors by enhancing the exterior surface charge storage. Adv Energy Mater 5:1500550

43. Liu S, Zhou J, Song H (2018) 2D Zn-hexamine coordination frameworks and their derived N-rich porous carbon nanosheets for ultrafast sodium storage. Adv Energy Mater 8:1800569

44. Xu X, Liu J, Liu Z, Shen J, Hu R, Liu J, Ouyang L, Zhang L, Zhu M (2017) Robust pitaya-structured pyrite as high energy density cathode for high-rate lithium batteries. ACS Nano 11:9033-9040

45. Jian Z, Xing Z, Bommier C, Li Z, Ji X (2016) Hard carbon microspheres: potassium-ion anode versus sodium-ion anode. Adv Energy Mater 6:1501874

46. Bulusheva LG, Okotrub AV, Kurenya AG, Zhang H, Zhang H, Chen X, Song H (2011) Electrochemical properties of nitrogen-doped carbon nanotube anode in Li-ion batteries. Carbon 49:4013-4023

47. Wang Z, Qie L, Yuan L, Zhang W, Hu X, Huang Y (2013) Functionalized N-doped interconnected carbon nanofibers as an anode material for sodium-ion storage with excellent performance. Carbon 55:328-334

48. Cao Y, Xiao L, Sushko ML, Wang W, Schwenzer B, Xiao J, Nie Z, Saraf LV, Yang Z, Liu J (2012) Sodium ion insertion in hollow carbon nanowires for battery applications. Nano Lett 12:3783-3787

49. Zhong J, Yi F, Gao A, Shu D, Huang Y, Li Z, Zhu W, He C, Meng T, Zhao S (2017) Preparation of 3D reduced graphene oxide/ $\mathrm{MnO}_{2}$ nanocomposites through a vacuum-impregnation method and their electrochemical capacitive behavior. ChemElectroChem 4:1088-1094

\section{Figures}




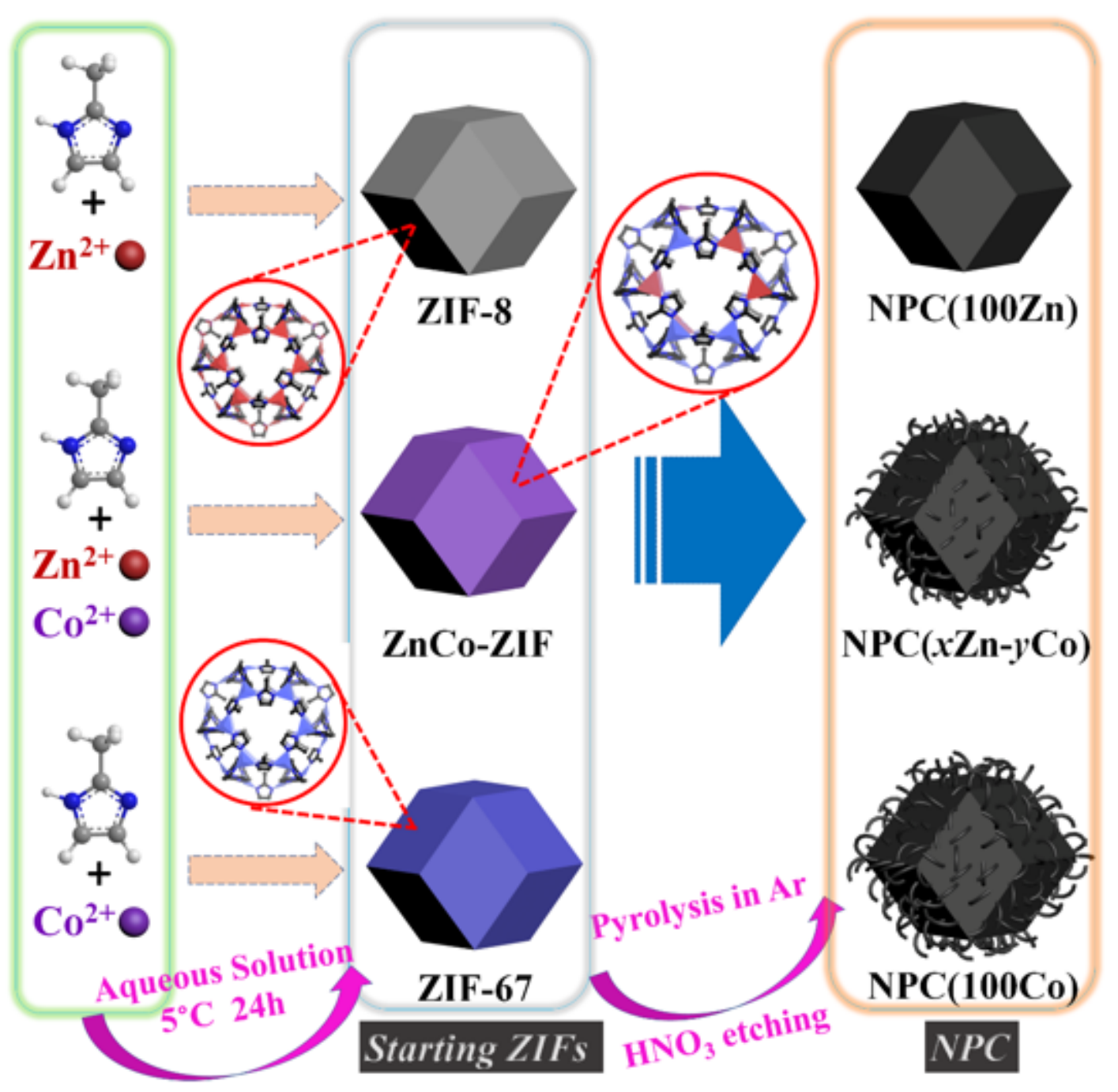

Figure 1

Schematic illustration for the fabrication of NPCs. 


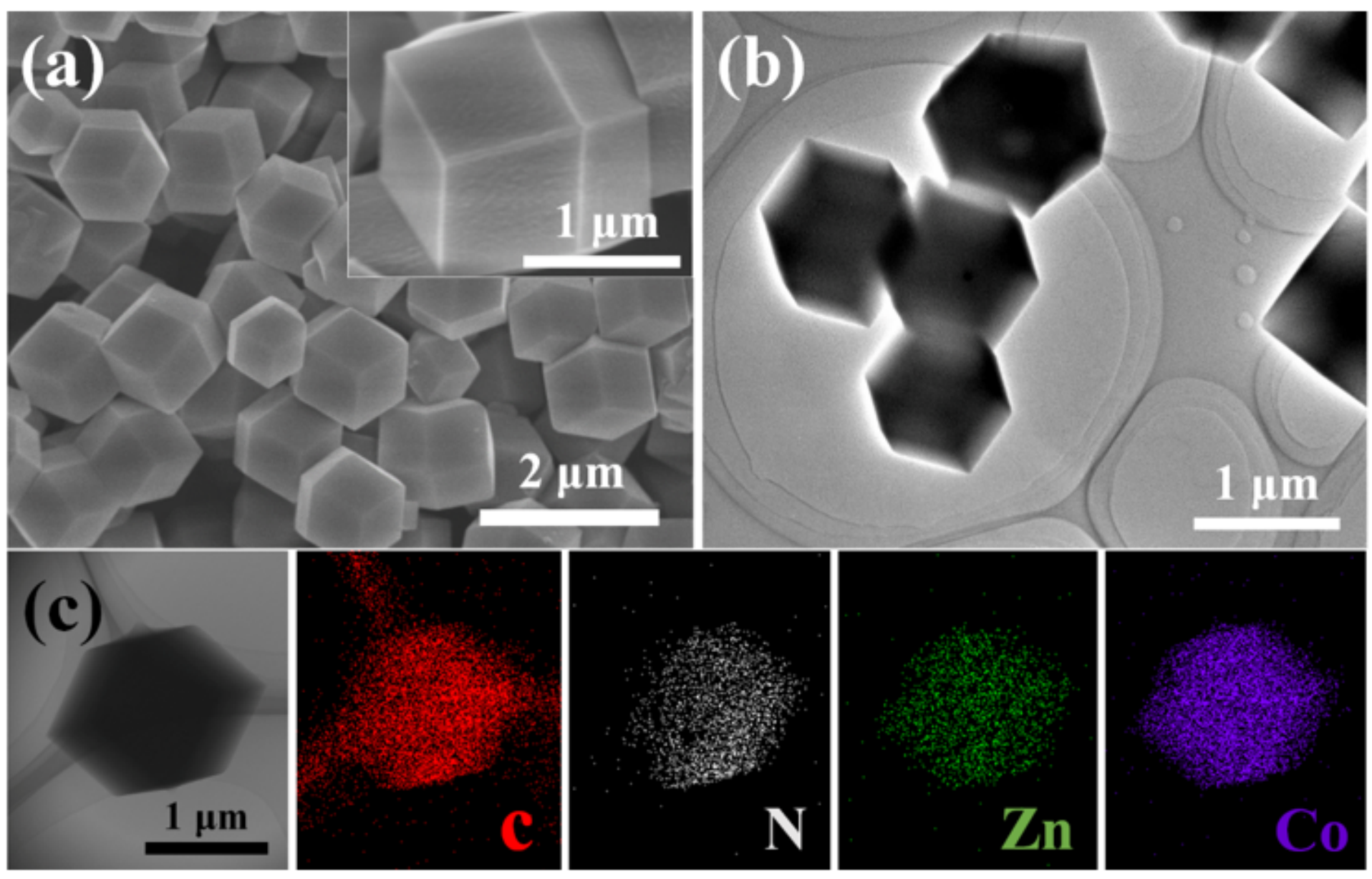

Figure 2

SEM (a), TEM (b) and EDS mapping (c) images of 20Zn80Co-ZIF. 

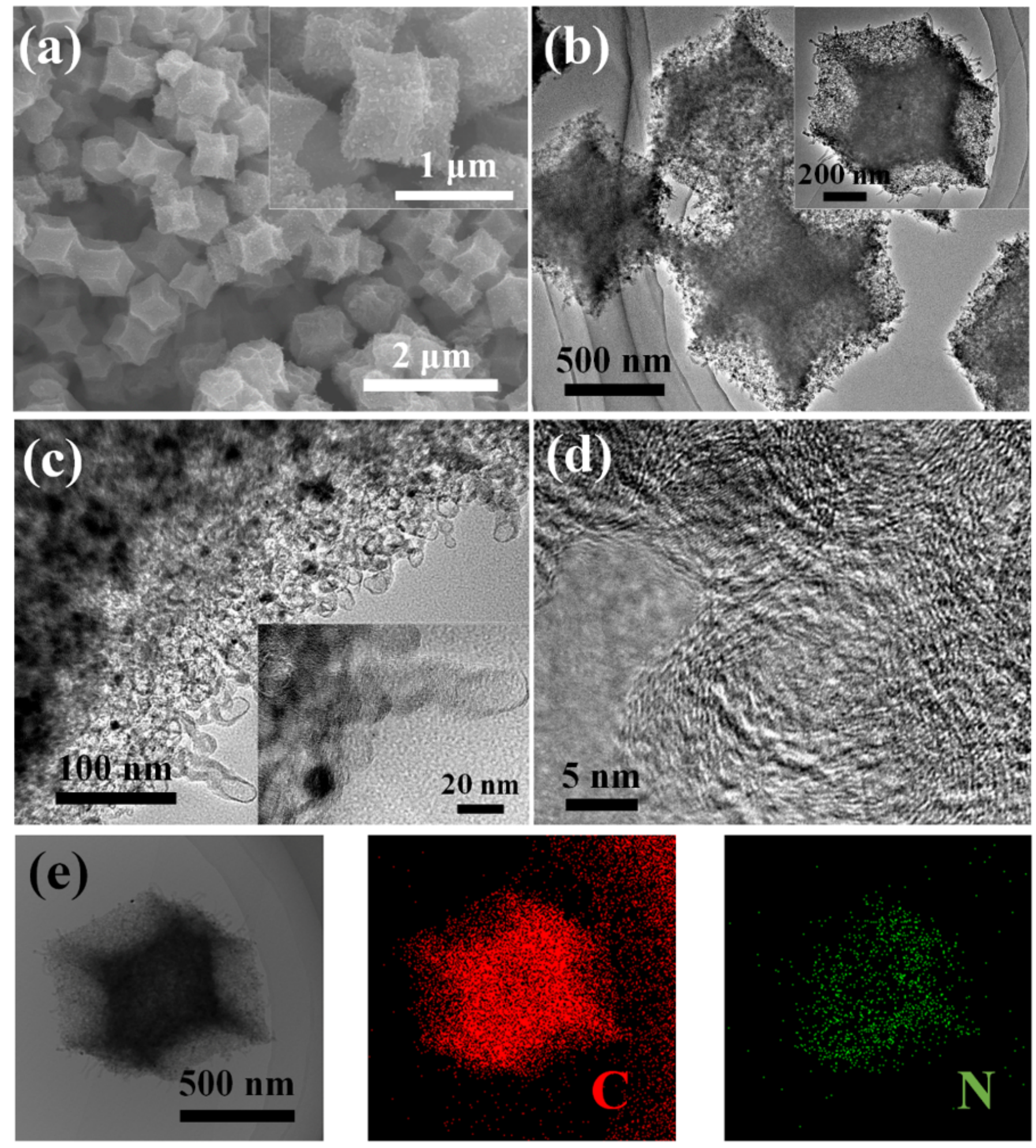

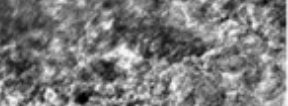
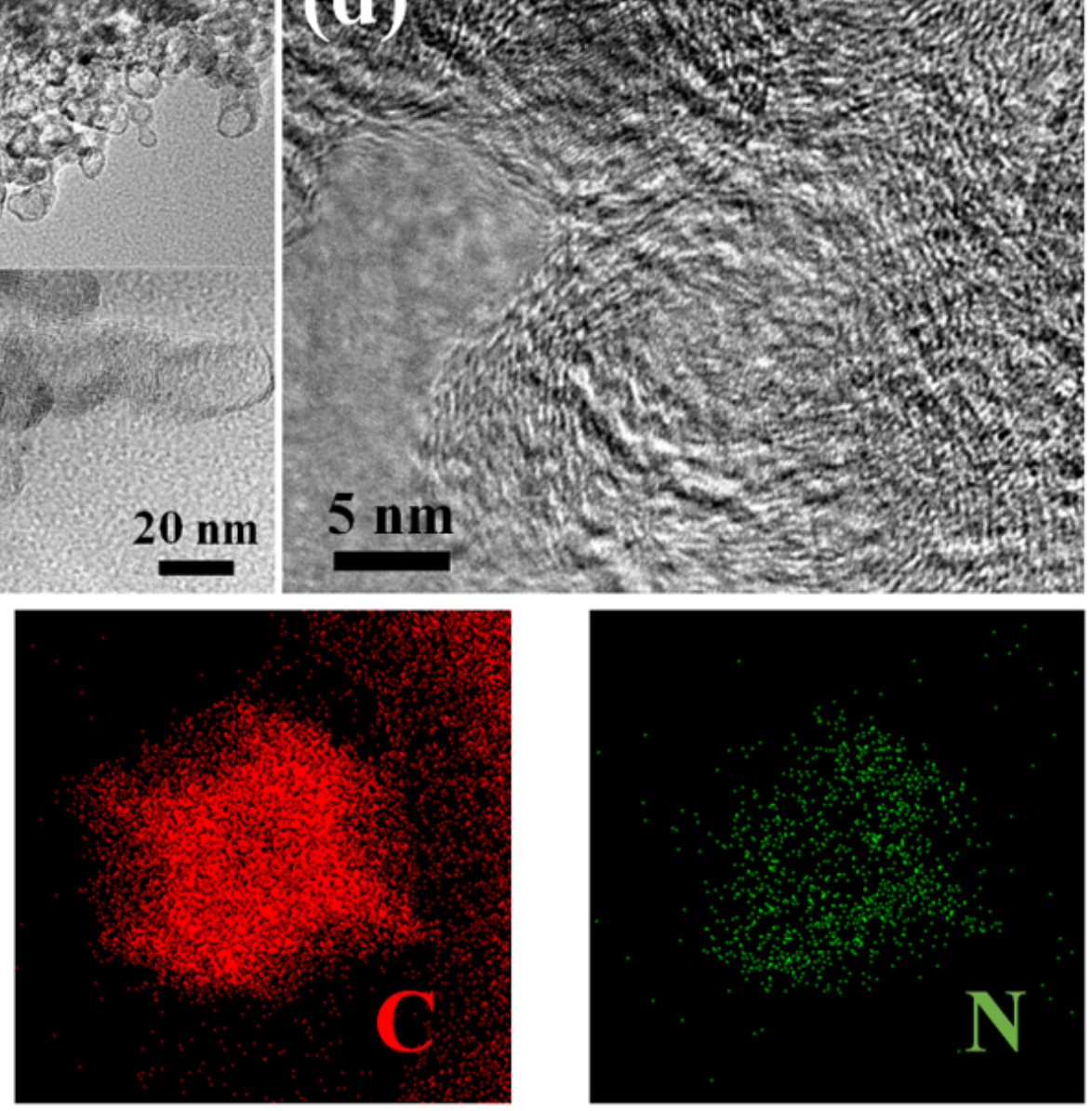

Figure 3

SEM (a), TEM (b, c), HRTEM (d) and EDS mapping (e) images of NPC(20Zn-80Co)-600 ${ }^{\circ} \mathrm{C}$. 

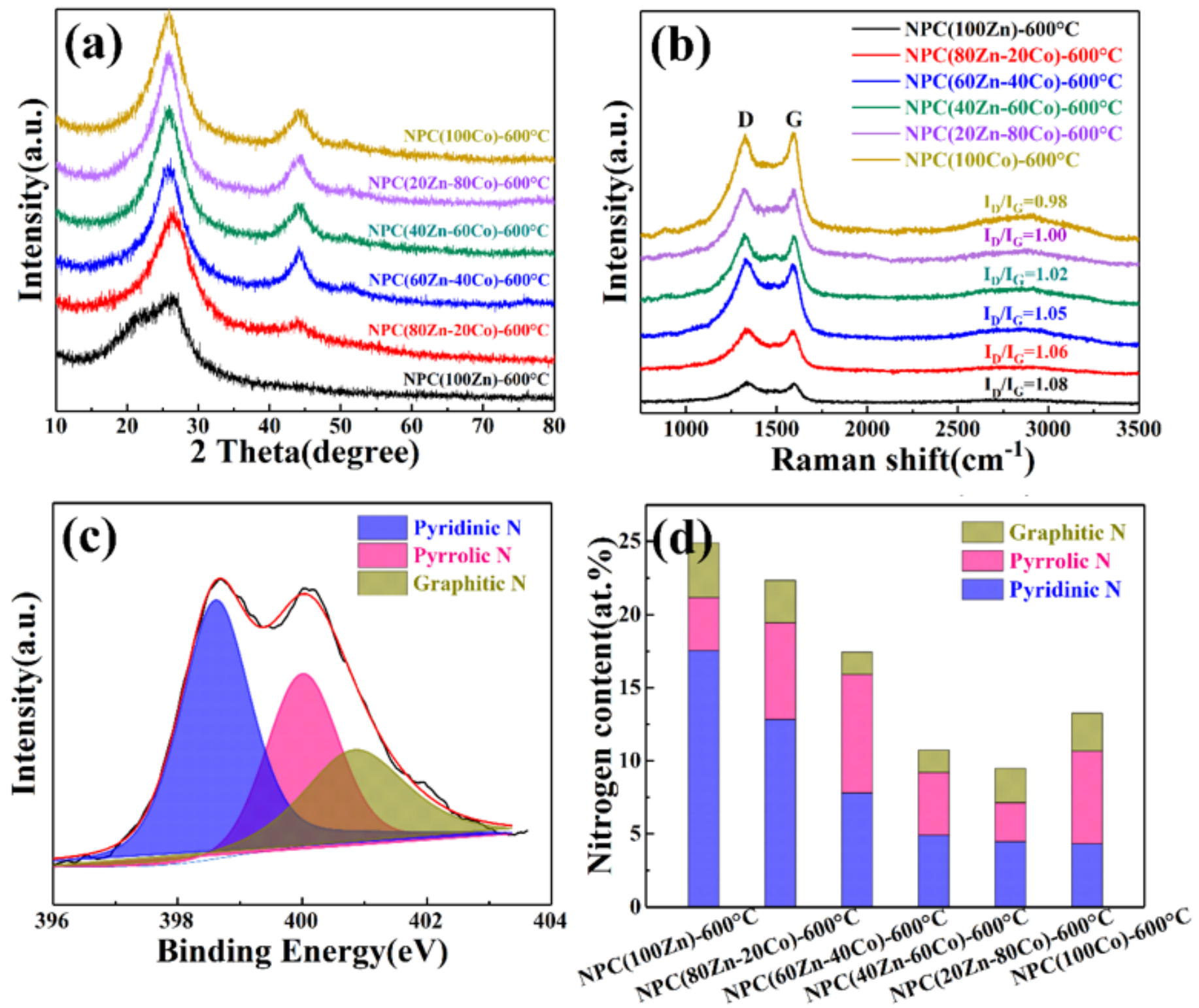

Figure 4

XRD patterns (a) and Raman spectra (b) of NPC(xZn-yCo)- $600^{\circ} \mathrm{C}, \mathrm{N} 1 \mathrm{~s}$ spectrum of $\mathrm{NPC}(20 \mathrm{Zn}$ $80 \mathrm{Co})-600^{\circ} \mathrm{C}$ (c) and the overall N-doping contents of $\mathrm{NPC}(x Z n-y C o)-600^{\circ} \mathrm{C}(\mathrm{d})$. 

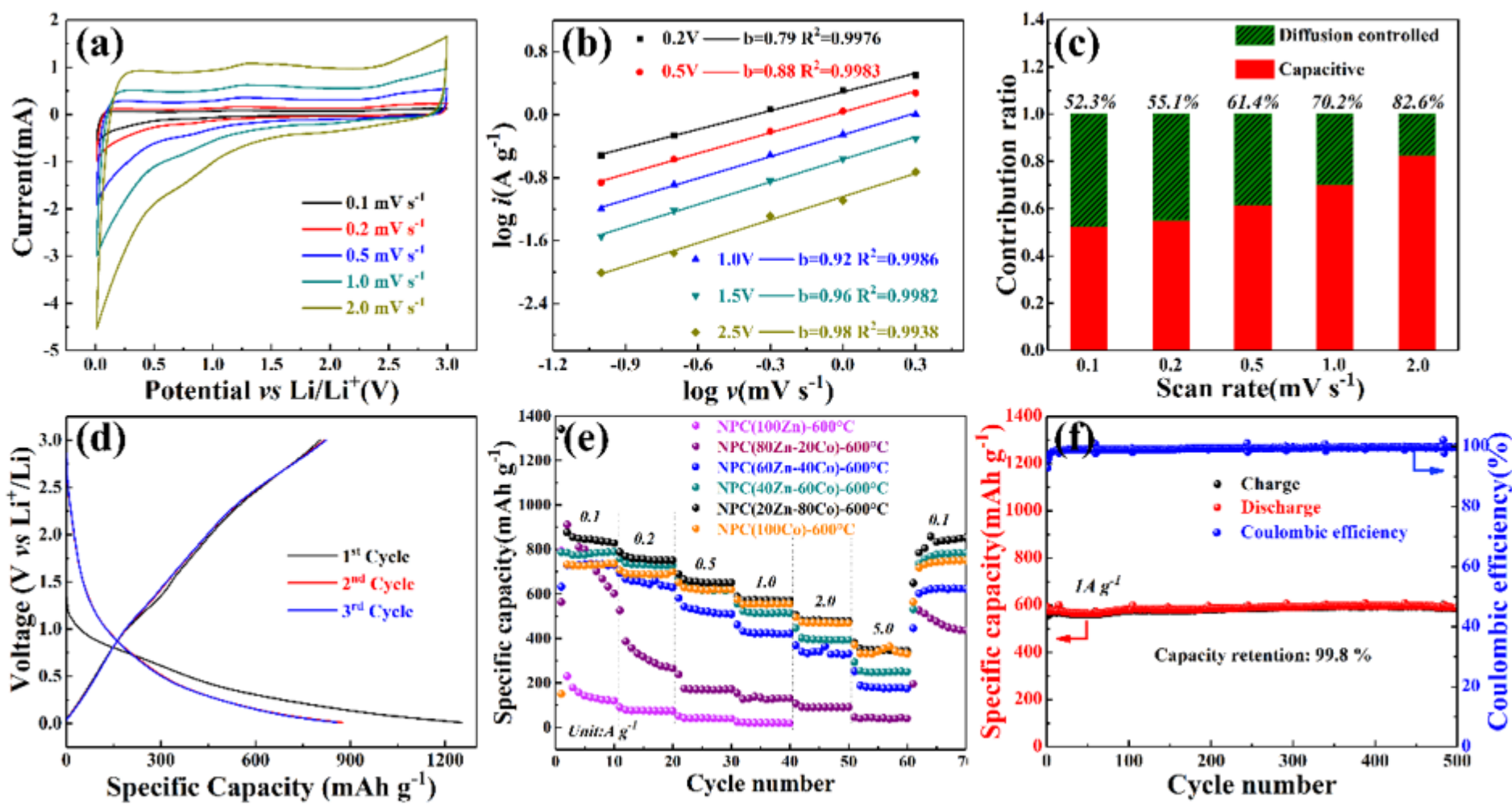

Figure 5

Li+ storage performance: (a) CV curves of NPC(20Zn-80Co)- $600^{\circ} \mathrm{C}$ at different scan rates (from 0.1 to 2 $\mathrm{mV} \mathrm{s}-1)$, (b) Relationship between current and scan rate of NPC $(20 \mathrm{Zn}-80 \mathrm{Co})-600^{\circ} \mathrm{C}$, (c) Contribution ratio of capacitive and diffusion controlled at different scan rate, (d) First three GCD curves of NPC(20Zn$80 \mathrm{Co})-600^{\circ} \mathrm{C}$ at current density of $100 \mathrm{~mA} \mathrm{g-1}$, (e) Rate capability of NPC(xZn-yCo)-600 ${ }^{\circ} \mathrm{C}$, (f) Cycling stability of NPC(20Zn-80Co)-600 ${ }^{\circ} \mathrm{C}$ at $1 \mathrm{~A}$ g- 1 for 500 cycles. 

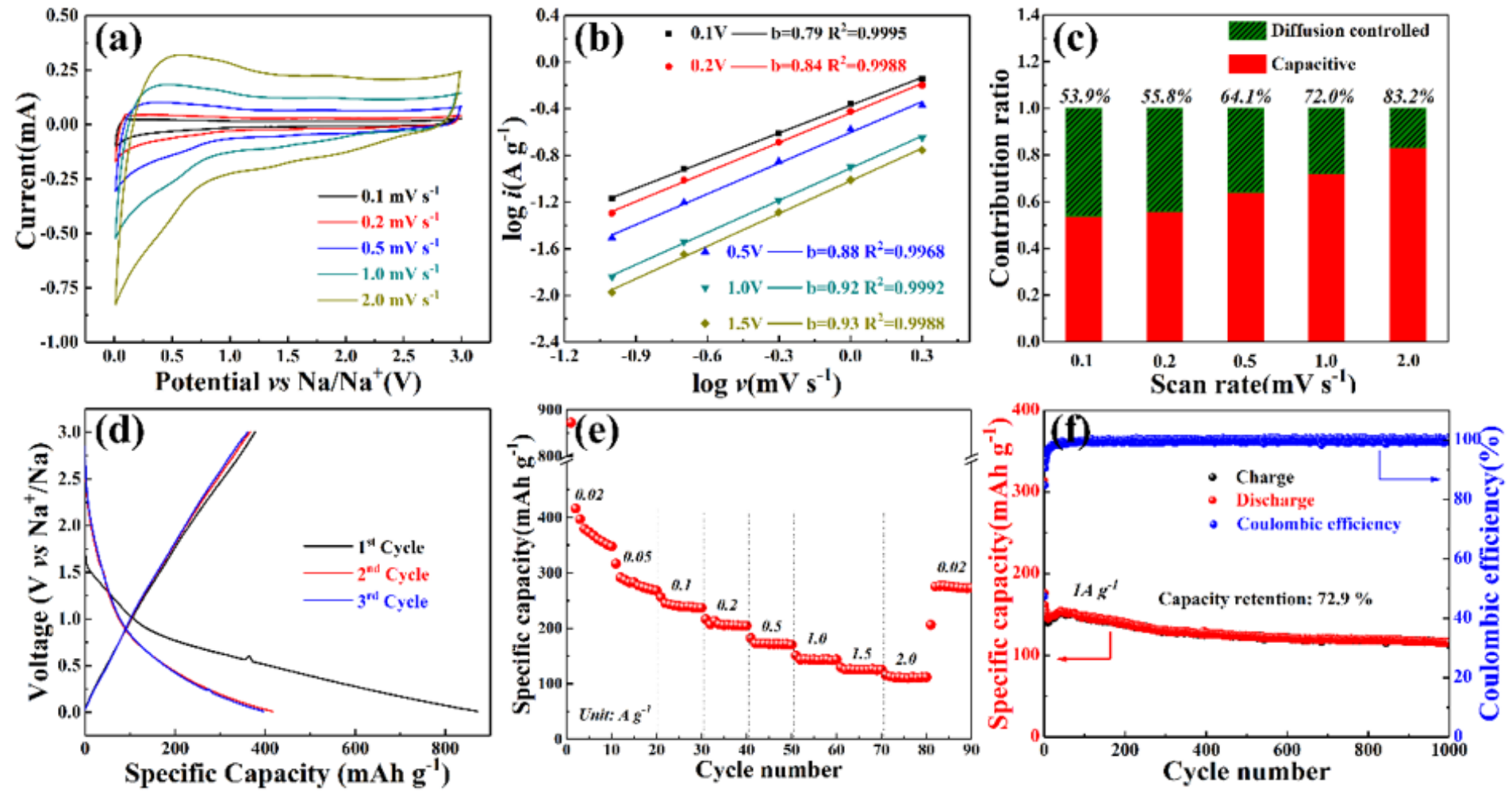

Figure 6

$\mathrm{Na}+$ storage performance of $\mathrm{NPC}(20 \mathrm{Zn}-80 \mathrm{Co})-600^{\circ} \mathrm{C}$ : (a) CV curves at different scan rates ranging from 0.1 to $2 \mathrm{mV} \mathrm{s}-1$, (b) Relationship between current and scan rate, (c) Contribution ratio of capacitive and diffusion controlled at different scan rate, (d) First three GCD curves at current density of $0.02 \mathrm{~A} \mathrm{g-1}$, (e) Rate capability and (f) Cycling stability at $1 \mathrm{~A} \mathrm{g-1}$ for 1000 cycles.

\section{Supplementary Files}

This is a list of supplementary files associated with this preprint. Click to download.

- SupportingInformation.docx 